\title{
Measurement and Analysis of Electromagnetic Field Strength in Port Harcourt and its Environs Due to Treasure FM Radio Transmitter
}

\author{
B. I. Bakare and J. C. Ozogbuda
}

\begin{abstract}
This paper Presents the measurement of electromagnetic field strength of Treasure FM transmitter operating at a frequency of $98.5 \mathrm{MHz}$ in Port Harcourt and its environs with the aid of an Automated Band Scanner GPS system. The measurement was carried out by taking the radio Station's transmitter as a reference point at the Centre and selecting 24 measuring points around the transmitter. These points were selected with $1 \mathrm{~km}$ spacing taken as the interval between two measuring points, summing up to a total of $6 \mathrm{~km}$ due North, East, West and South of the Radio Transmitter respectively. The result obtained was critically analyzed and interpreted with the aid of an attenuation decay curve. The behavior of the signal was seen to be a function of the Ground Constant of the terrain, reflection of the signal from the earth surface, Diffraction by obstacles and transmitter parameters such as transmitter Power, Antenna Gain and Antenna Height.
\end{abstract}

Index Terms-Attenuation; Measurement; Signal Strength; Transmitter.

\section{INTRODUCTION}

A radio wave is an Electromagnetic wave which emanates from a radiating source. The radio wave assumes all the properties of a plane wave; the wave-front is the plane which contains the Electric $(\mathrm{E})$ and Magnetic $(\mathrm{H})$ vectors and is at right angle to the direction of propagation and power flow. Usually, it is convenient to carry out studies in terms of the electric component, $\mathrm{E}$ of the wave which is known as the electric field strength of the wave (Radio wave). The quantitative measure of the strength of an Electric field is known as the Electric field strength (Intensity) measurement. From Electrostatics studies, we can loosely define Electric field strength at a point as the force on a unit positive charge at that point and is measured in Newton's per Coulomb or Volts per meter (Vm-1). The level of Electromagnetic field strength needed to provide adequate reception in the presence of an interfering signal(s) is referred to as the usable field strength. [1]

Treasure FM transmitter located at NTA premises Choba Road, Mgbuoba (latitude: 451'48.52"N, longitude: $6^{\circ} 57^{\prime} 48.80^{\prime \prime} \mathrm{E}$ ) transmits at a frequency of $98.5 \mathrm{MHz}$ with an output power of $3 \mathrm{KW}$. The radio signal is propagated using space wave propagation mode. The measurement of electromagnetic field strength of Treasure FM signals at different locations, that is, locations due EAST, NORTH, WEST and SOUTH of the Radio Transmitter respectively with $1 \mathrm{Km}$ interval was obtained using an automated mobile Band Scanner GPS system.

The transmitter has the following features: Antenna Load impedance: 50 ohms, Reflected power: 32watt, Polarization of Antenna: vertical polarization, Feeder line size:3/8 inch, Mast height: 540ft, Voltage of AVR:400V, Voltage of transmitter:24.8kv, Current of transmitter:45.7A and Wavelength:3.0456m

This paper presents the values and analysis of the measured Electromagnetic field strength of Treasure FM station at different locations, that is, locations due EAST, NORTH, WEST and SOUTH of the Radio Transmitter respectively with $1 \mathrm{Km}$ interval between two measuring points using an automated mobile Band Scanner GPS system

The measuring points were selected with $1 \mathrm{~km}$ spacing taken as the interval between two measuring points, summing up to a total of $6 \mathrm{~km}$ due North, East, West and South of the Radio Transmitter respectively. Fig. 1 below show the location of Treasure FM Radio Station in Port Harcourt, Nigeria

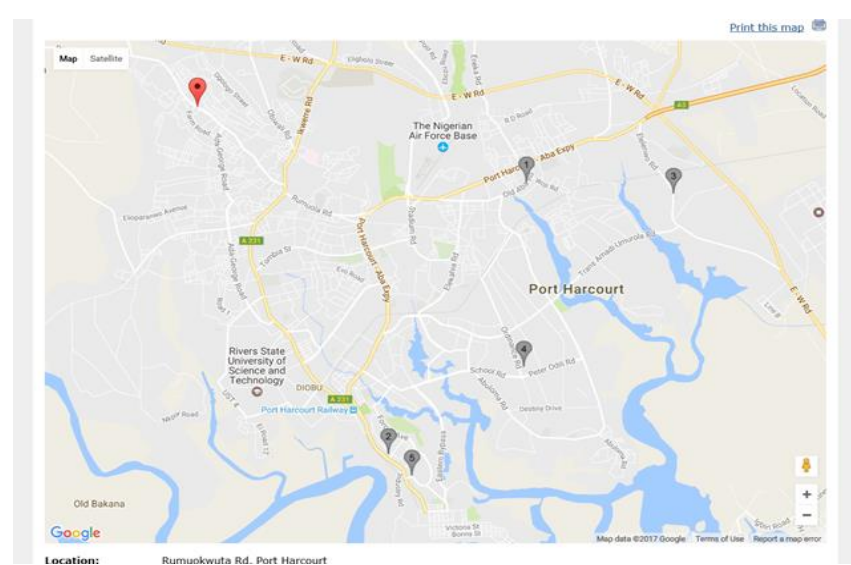

Fig. 1. Google Earth Map showing the Location of Treasure FM Radio Station in Port Harcourt, Nigeria

\section{Mode of Propagation of Electromagnetic WaVes}

Propagation of electromagnetic waves occurs in the different modes as shown in the Fig. 2 below 


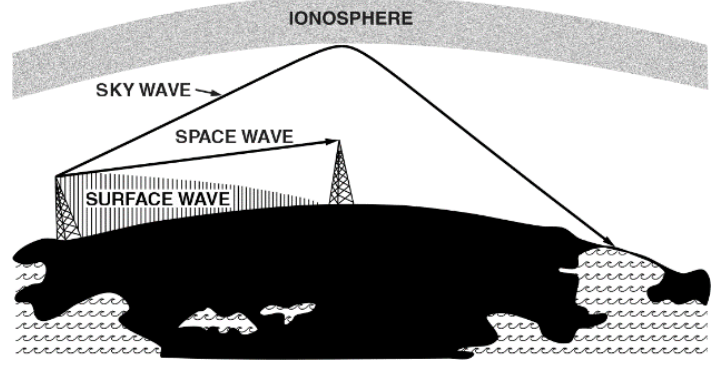

Fig. 2. Modes of propagation of electromagnetic waves

\section{A. Ground Wave Propagation}

The propagation of the waves along the surface of the earth is called ground wave propagation. It is also known as surface wave propagation. These waves have the ability to propagate along the surface of earth as shown in Fig. 3 below. These waves bend around the obstacles which come in the path of these waves. Due to this rounding through the obstacles, the intensity of the electromagnetic waves will decrease rapidly. [2], [5]

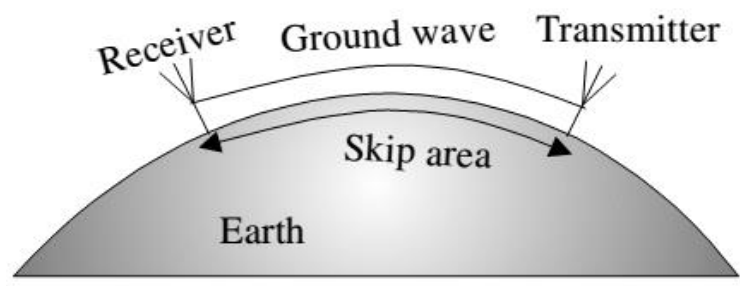

Fig. 3. Ground wave propagation

\section{B. Sky Wave Propagation:}

Sky waves have frequency range between $2 \mathrm{MHz}$ to $30 \mathrm{MHz}$. These radio waves have the ability to pass through earth's atmosphere. The ionosphere of our earth reflects these rays very efficiently. When these rays move along the atmosphere then their movement is from transmitter towards the receiver antenna as shown in Fig. 4 below This is called sky wave propagation of the waves [2].

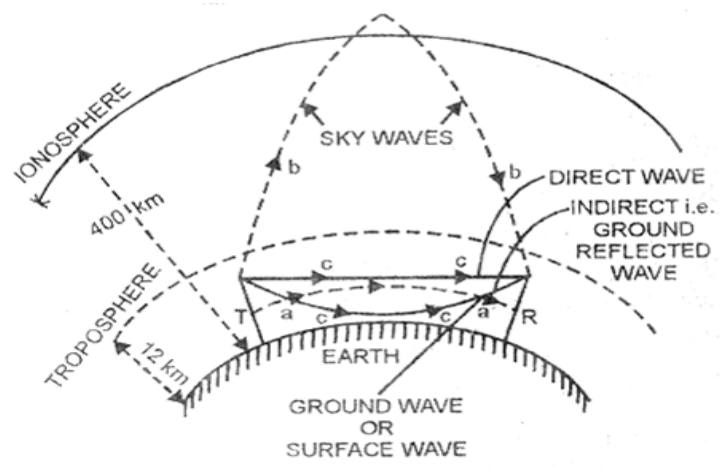

Fig. 4. Sky wave propagation

\section{Space Wave Propagation:}

The space waves are the radio waves of very high frequency (i.e. between $30 \mathrm{MHz}$ to $300 \mathrm{MHz}$ or more). The space waves can travel through atmosphere from transmitter antenna to receiver antenna either directly or after reflection from ground in the earth's stratosphere region as shown in Fig. 5 below. That is why the space wave propagation is also called tropospheric propagation. [2], [5].

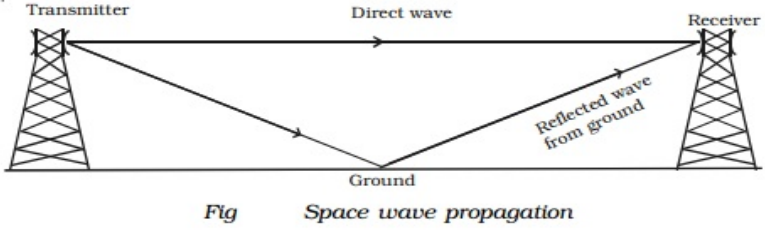

Fig. 5. Space wave propagation

\section{MAthematical Description OF EleCtRomagnetiC FIELD}

There are different mathematical ways of representing the electromagnetic field. The first one views the Electric and Magnetic fields as three-dimensional vector fields. These vector fields each have a value defined at every point of space and time and are thus often regarded as functions of the space and time coordinates. As such, they are often written as $\mathbf{E}(\mathrm{x}, \mathrm{y}, \mathrm{z}, \mathrm{t})$ electric field and $\mathbf{B}(\mathrm{x}, \mathrm{y}, \mathrm{z}, \mathrm{t})$ magnetic field.

If only the electric field (E) is non-zero, and is constant in time, the field is said to be an Electrostatic field. Similarly, if only the magnetic field (B) is non-zero and is constant in time, the field is said to be a Magneto static field. However, if either the electric or magnetic field has a timedependence, then both fields must be considered together as a coupled Electromagnetic field using Maxwell's equations. Maxwell's equations can be written in tensor form, generally viewed by physicists as a more elegant means of expressing physical laws [3], [6].

The behaviour of electric and magnetic fields, whether in cases of electrostatics, magneto statics, or electrodynamics (electromagnetic fields), is governed by Maxwell's equations. In the vector field formalism, these are:

$$
\begin{aligned}
& \nabla \cdot \mathbf{E}=\frac{\rho}{\varepsilon_{0}} \\
& \nabla \cdot \mathbf{B}=0 \\
& \nabla \times \mathbf{E}=-\frac{\partial \mathbf{B}}{\partial t} \\
& \nabla \times \mathbf{B}=\mu_{0} \mathbf{J}+\mu_{0} \varepsilon_{0} \frac{\partial \mathbf{E}}{\partial t}
\end{aligned}
$$

where $\rho \rho$ is the charge density, which can (and often does) depend on time and position, $\varepsilon_{0} \varepsilon_{0}$ is the permittivity of free space, $\mu_{0}$ is the permeability of free space, and $\mathbf{J}$ is the current density vector, also a function of time and position. The units used above are the standard SI units. Inside a linear material, Maxwell's equations change by switching the permeability and permittivity of free space with the permeability and permittivity of the linear material in question. Inside other materials which possess more complex responses to electromagnetic fields, these terms are often represented by complex numbers, or tensors [3],[6]. 


\section{GROUnd CONSTANTS}

The relative permittivity and Conductivity Values for different type of ground is shown in Table I below

\begin{tabular}{clll}
\multicolumn{4}{c}{ TABLE I: GROUND CONSTANT VALUES } \\
\hline \hline \multirow{2}{*}{ S/No } & $\begin{array}{c}\text { Type of } \\
\text { Ground }\end{array}$ & $\begin{array}{c}\text { Relative } \\
\text { Permittivity }\end{array}$ & $\begin{array}{c}\text { Conductivity } \\
(\boldsymbol{\Omega m}-\mathbf{1})\end{array}$ \\
\hline 1. & Sea water & 80 & 5 \\
2. & Fresh water & 80 & 0.005 \\
3. & Moist soil & $15-30$ & $0.005-0.01$ \\
4. & Rocky ground & 7 & 0.001 \\
5. & Dry soil & 4 & $0.001-0.01$ \\
6. & march & 30 & 0.11 \\
7. & Average soil & 15 & 0.028 \\
8. & Desert & 3 & 0.11 \\
\hline \hline
\end{tabular}

\section{MATERIALS AND Methods}

\section{A. Measurement Procedure}

The equipment for the electromagnetic field strength measurements is shown in Fig. 6 below:

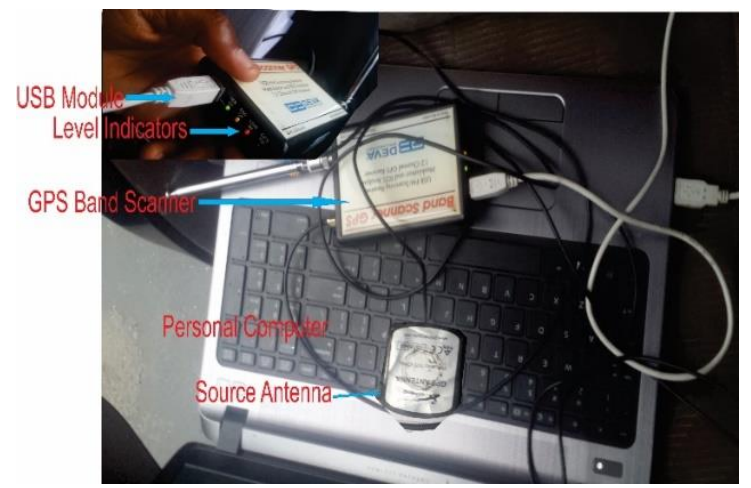

Fig. 6. The equipment used for the measurement

$>$ The receiver system (Band Scanner GPS) - to determine is received by the test antenna

$>$ A Personal Computer (PC) system - serves as the visual output of the Band Scanner GPS.

$>$ A module such as a USB cord - To power the receiver system and also serves as a medium or interface for the visual output.

Band Scanner GPS is a tool used to evaluate FM broadcast band and to log station identification parameters such as electromagnetic field strength, bandwidth, Received power at a distance and radio data system strength. "Band Scanner GPS" is a Google Earth compatible tool for visualization of selected FM Radio measurements [4].

After connecting the device to the PC where the software is already installed, the USB indicator will become bright green. The software will adjust the unit with the initial data. In case of previous usage of the device, the last settings like frequency and levels will be assigned in the device. If everything is Okay and no problems are detected the software will look like Fig. 7:

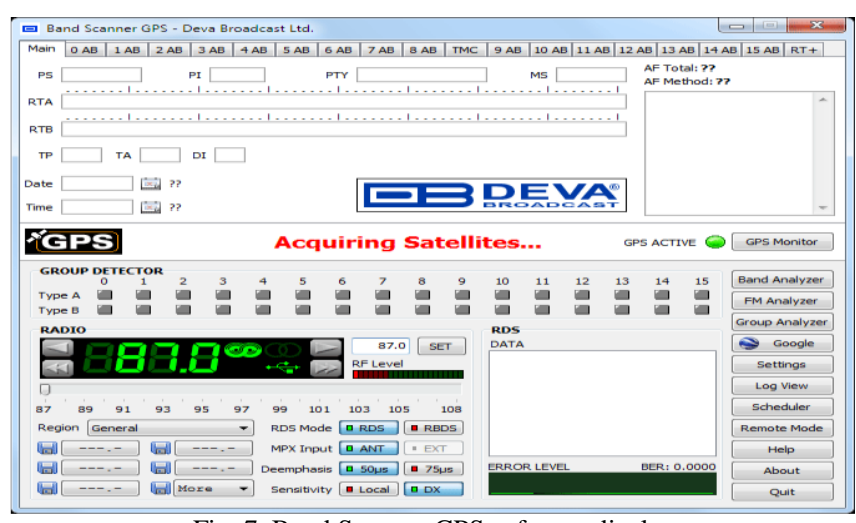

Fig. 7. Band Scanner GPS software display

\section{B. Selection of Data points}

As shown on the map of Fig. 8 about, six circles are drawn on the map taking Treasure FM Transmitter located at NTA premises Choba Road, Mgbuoba as the Centre point, a distance of $6 \mathrm{KM}$ radius at the four cardinal points taking $1 \mathrm{~km}$ apart from the transmitter was measured at different locations due North, South, East, and West respectively. This was easily achieved with the use of Google Earth application as it depicts the location of the transmitter after inputting its coordinates. With the help of Google Earth visual, $1 \mathrm{~km}$ intervals from the transmitter were easily projected and a measurement is taken with help of the GPS band scanner. The coordinates gotten from Google Earth application were easily imputed on the GPS Band Scanner since it's a Google Earth Compatible tool and can $\log$ stations identification parameters such as electromagnetic field strength, bandwidth, received power at a distance and radio data system strength [4].

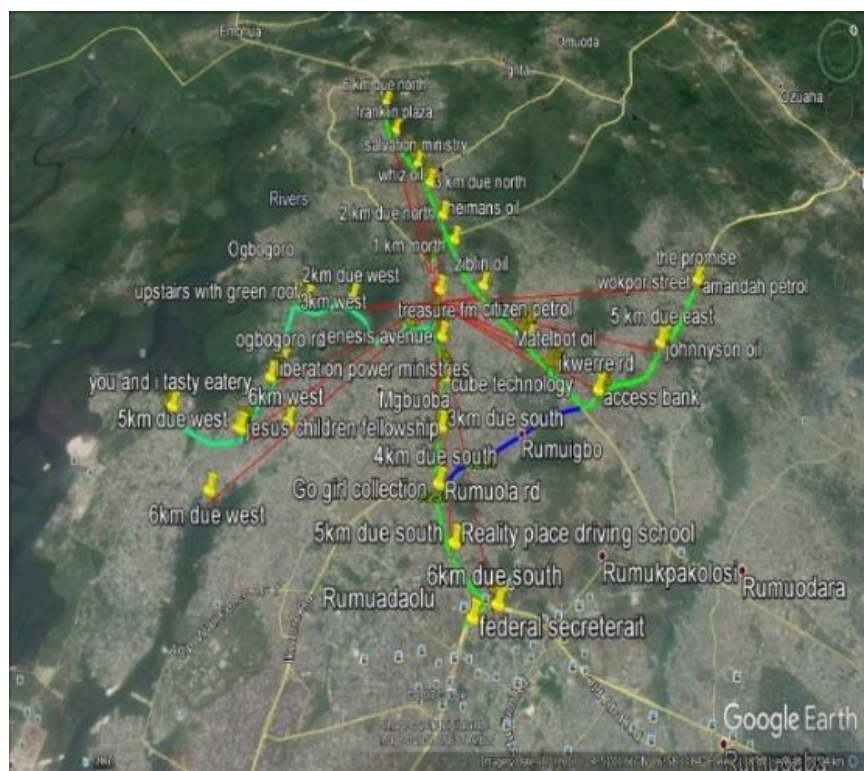

Fig. 8. Showing the 24 measuring points due East, West, North and South of the Transmitter 


\section{Presentation of Data}

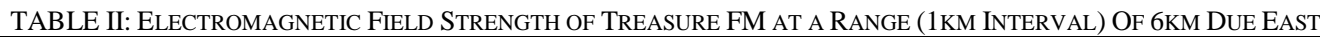

\begin{tabular}{|c|c|c|c|c|c|}
\hline S/No & $\begin{array}{l}\text { Distance from } \\
\text { transmitter }\end{array}$ & $\begin{array}{l}\text { Location Coordinates: } \\
\text { Latitude(Lat) and } \\
\text { longitude(long) } \\
\end{array}$ & $\begin{array}{l}\text { Measured value } \\
\quad(\mathrm{dB} \mu \mathrm{v})\end{array}$ & $\begin{array}{l}\text { Field strength } \\
\qquad \mu \mathrm{v} / \mathrm{m}\end{array}$ & $\begin{array}{c}\text { Time of } \\
\text { measurement }\end{array}$ \\
\hline 1 & $1 \mathrm{~km}$ East & $\begin{array}{l}\text { Lat: } 4^{\circ} 52^{\prime} 14.69^{\prime \prime} \mathrm{N} \\
\text { Long: } 6^{\circ} 58^{\prime} 9.17 " \mathrm{E}\end{array}$ & 52.6 & 0.0526 & $12: 57 \mathrm{pm}$ \\
\hline 2 & $2 \mathrm{~km}$ East & $\begin{array}{l}\text { Lat: } 4^{\circ} 52^{\prime} 9.51 " \mathrm{~N} \\
\text { Long:6 } 6^{\circ} 58^{\prime} 51.48^{\prime \prime} \mathrm{E}\end{array}$ & 48.3 & 0.02415 & 1:00pm \\
\hline 3 & $3 \mathrm{~km}$ East & $\begin{array}{c}\text { Lat: } 4^{\circ} 52^{\prime} 5.64^{\prime \prime} \mathrm{N} \\
\text { Long:6 } 6^{\circ} 59^{\prime} 25.06^{\prime \prime} \mathrm{E}\end{array}$ & 54.4 & 0.01813 & $1: 03 \mathrm{pm}$ \\
\hline 4 & 4km East & $\begin{array}{l}\text { Lat: } 4^{\circ} 52^{\prime} 19.36^{\prime \prime} \mathrm{N} \\
\text { Long:6 } 6^{\circ} 59^{\prime} 55.96 " \mathrm{E}\end{array}$ & 43.2 & 0.0108 & $1: 25 \mathrm{pm}$ \\
\hline 5 & $5 \mathrm{~km}$ East & $\begin{array}{l}\text { Lat: } 4^{\circ} 53^{\prime} 12.03^{\prime \prime} \mathrm{N} \\
\text { Long: } 7^{\circ} 0^{\prime} 9.29^{\prime \prime} \mathrm{E}\end{array}$ & 35.3 & 0.00706 & $1: 35 \mathrm{pm}$ \\
\hline 6 & $6 \mathrm{~km}$ East & $\begin{array}{l}\text { Lat: } 4^{\circ} 54^{\prime} 14.01 " \mathrm{~N} \\
\text { Long: } 7^{\circ} 0^{\prime} 0.44 " \mathrm{E}\end{array}$ & 48.6 & 0.0081 & $1: 38 \mathrm{pm}$ \\
\hline
\end{tabular}

TABLE III: Electromagnetic FIELD STRENGTH OF TREASURE FM AT A RANGE (1 KM INTERVAL) OF 6KM DUE NoRTH

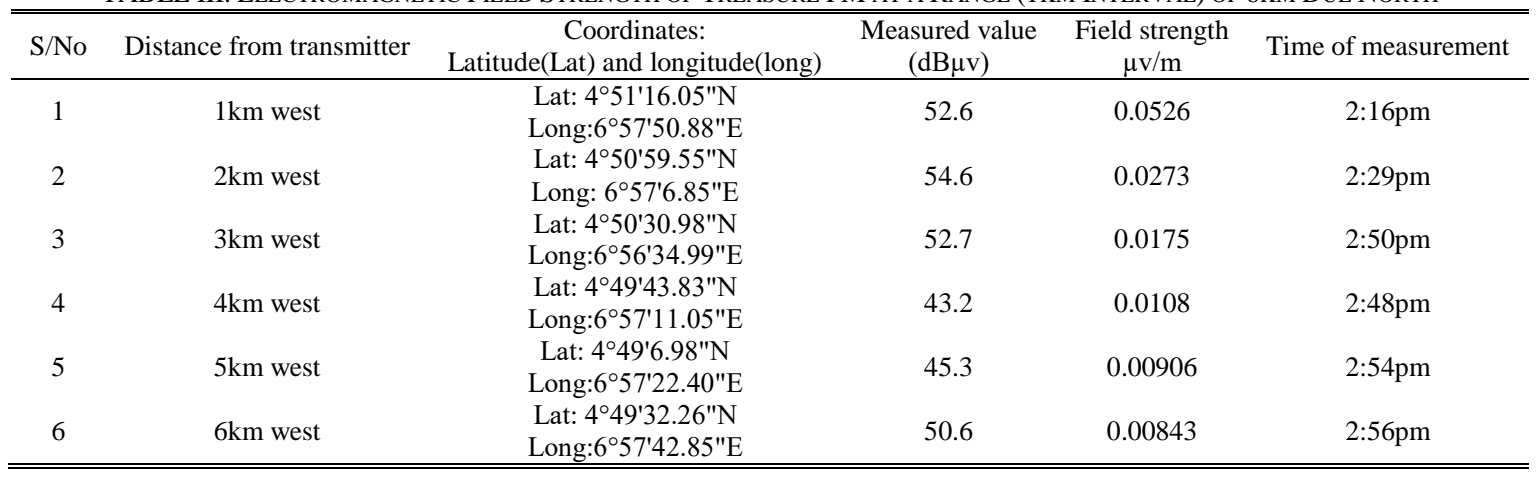

TABLE IV: EleCtromagnetic FIELD STRENGTH OF TREASURE FM AT A RANGE OF 6KM (1 KM INTERVAL) DUE West

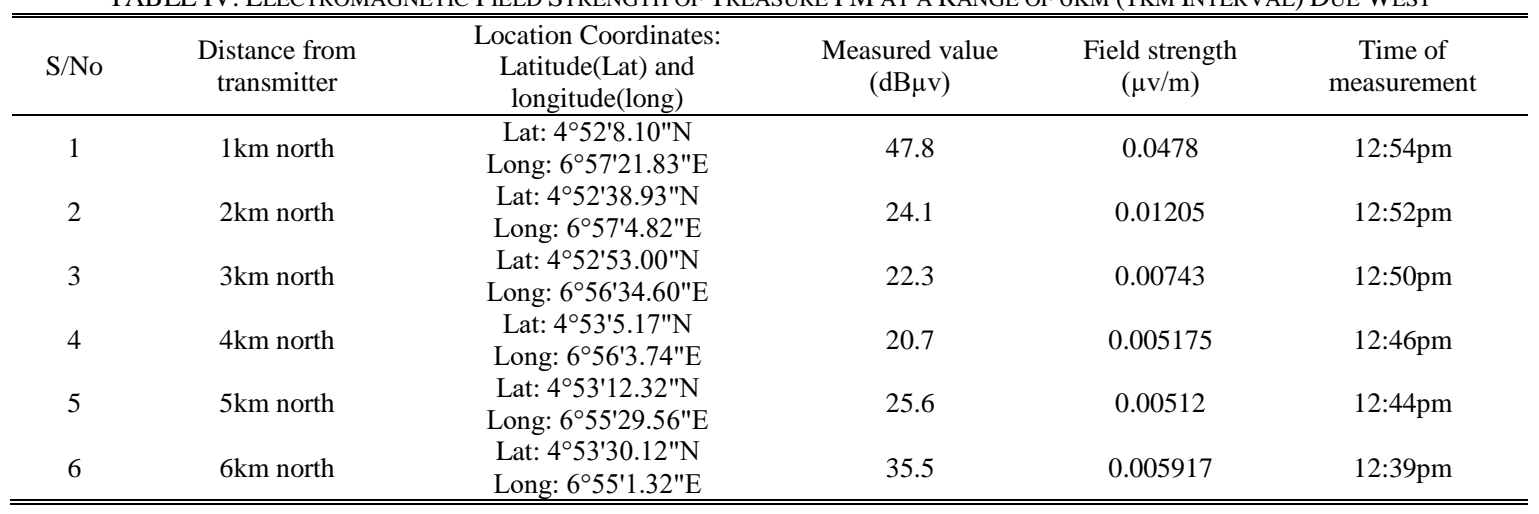

TABLE V: EleCtromagnetic FIELD STRENGTH OF TREASURE FM AT A RANGE OF 6KM (1 KM INTERVAL) DUE SOUTH

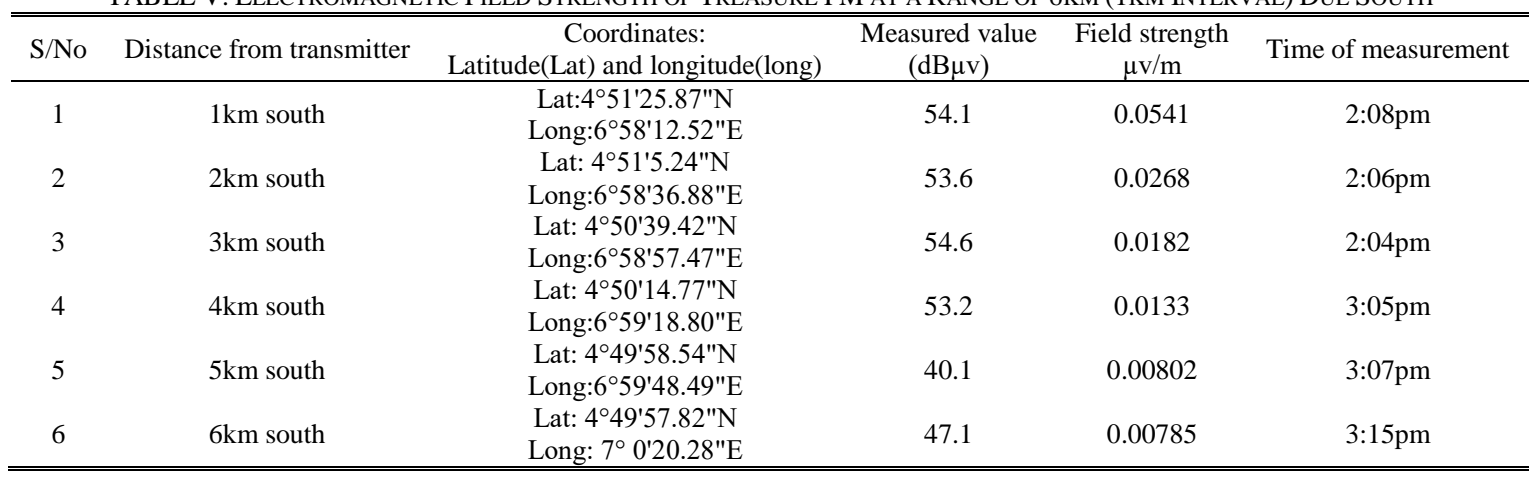




\section{RESULTS AND DISCUSSIONS}

\section{A. Results}

Graphical representation of the Field strength of Treasure FM 6km from the Transmitter due North, South, East and West are shown below

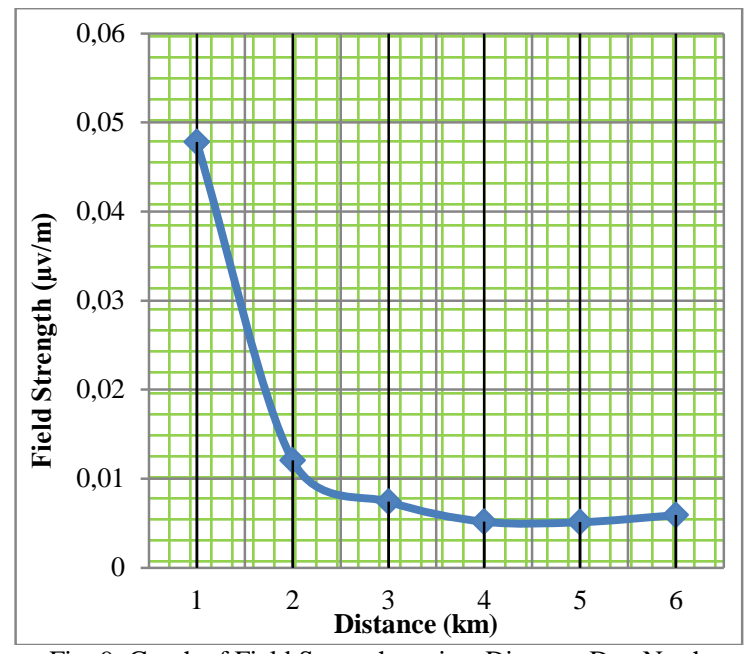

Fig. 9. Graph of Field Strength against Distance Due North

From Fig..9 above, it was observed that at $1 \mathrm{~km}$ away from the transmitter where the field strength was measured to be $0.0478 \mu \mathrm{v} / \mathrm{m}$, the signal was very high and at $2 \mathrm{~km}$ away from the transmitter, the value of the field strength decreased considerably to $0.01205 \mu \mathrm{v} / \mathrm{m}$, however, between $3 \mathrm{~km}$ from the transmitter to $6 \mathrm{~km}$ there was only slight changes observed in the value of the Field Strength

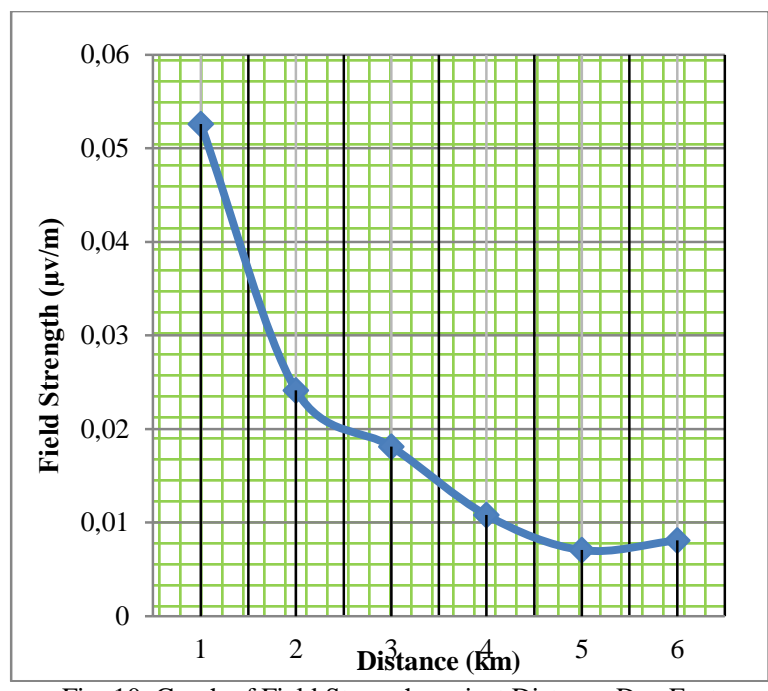

Fig. 10. Graph of Field Strength against Distance Due East

Fig. 10 above shows the graphical representation of the field strength of Treasure FM due East $6 \mathrm{~km}$ away from the transmitter. At $1 \mathrm{~km}$ from the transmitter the signal at the time of measurement was significantly high having a field strength of $0.0526 \mu \mathrm{v} / \mathrm{m}$ and decreased considerably to $0.02415 \mu \mathrm{v} / \mathrm{m}$ at $2 \mathrm{~km}$ away from the transmitter. The signal decreased slightly from $3 \mathrm{~km}$ to $5 \mathrm{~km}$ away from the transmitted and also increased slightly at $6 \mathrm{~km}$ away from the transmitter at the time.

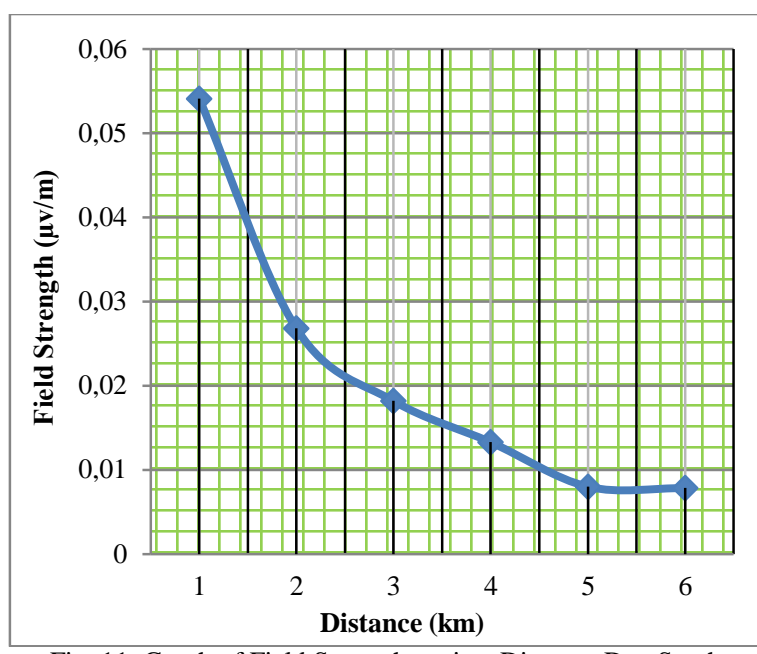

Fig. 11. Graph of Field Strength against Distance Due South

From the graphical representation of the field strength due South it was observed that at $1 \mathrm{~km}$ away from the transmitter where the field strength was measured to be $0.0541 \mu \mathrm{v} / \mathrm{m}$, the signal was very high and at $2 \mathrm{~km}$ away from the transmitter, the value of the field strength decreased considerably to $0.0268 \mu \mathrm{v} / \mathrm{m}$, however, between $3 \mathrm{~km}$ from the transmitter to $6 \mathrm{~km}$ there was only slight changes observed in the calculated Field Strength value

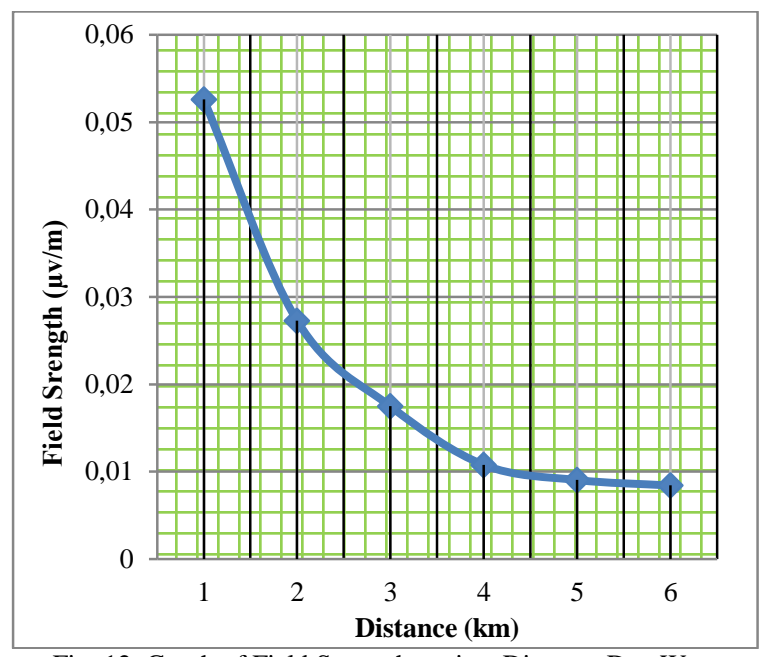

Fig. 12. Graph of Field Strength against Distance Due West

Fig. 12 shows the graphical representation of the field strength due West and it was observed from the figure that at $1 \mathrm{~km}$ away from the transmitter where the field strength was measured to be $0.0526 \mu \mathrm{v} / \mathrm{m}$, the signal was very high and at $2 \mathrm{~km}$ away from the transmitter, the value of the field strength decreased considerably to $0.02783 \mu \mathrm{v} / \mathrm{m}$, however, between $3 \mathrm{~km}$ from the transmitter to $6 \mathrm{~km}$ there was only slight changes observed in the Field Strength value.

\section{B. Discussions}

For an ideal isotropic radiating antenna, the signal Strength is always equal in all directions, but for this work the Signal Strength is not the same in all direction as the signal level due north is lowest relative to east, south and west as shown in Fig. 13 below 


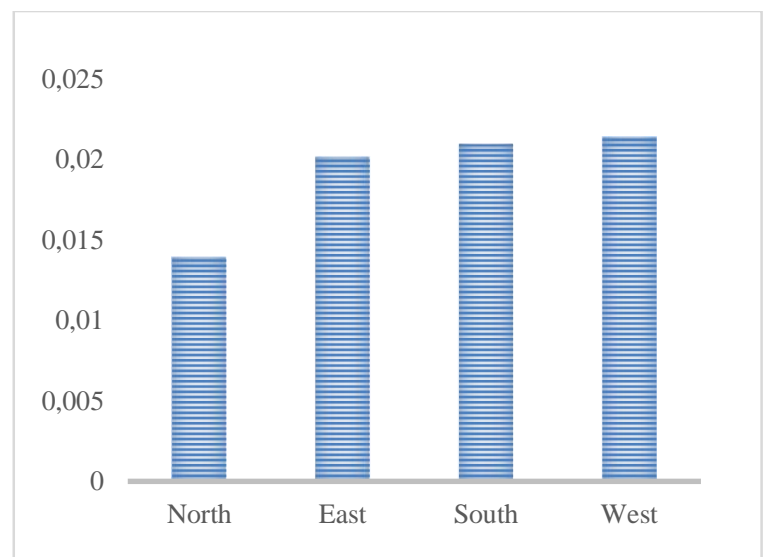

Fig. 13. Comparative Analysis of the Signal Strength in all directions

In summary, the figure above shows the Signal Strength level due North, East, South and West of the transmitter at a $6 \mathrm{~km}$ range. The graph indicates the lowest field strength from transmitter due North relative to the highest due west of the transmitter. This is due to factors such as weather, topography of the area, mode of propagation and the Ground Constant at the time of measurement

\section{CONCLUSION}

This paper was able to demonstrate how electromagnetic field strength of Treasure FM Radio can be measured and from the analysis of the result gotten from the measurement, the electromagnetic field strength of Treasure FM signal within $6 \mathrm{~km}$ range from the transmitter was highest due West and lowest due North of the transmitter at the time of measurement. it was observed that at certain distances close to the transmitter the field strength at some locations were high while at locations far from the transmitter, the Received Signal Strength (RSS) was low.

The behavior of the signal was seen to be a function of the Ground Constant of the terrain, reflection of the signal from the earth surface, Diffraction by obstacles and transmitter parameters such as transmitter Power, Antenna Gain and Antenna Height

\section{REFERENCES}

[1] B.I. Bakare, S. Orike and C.S. Gabriel (November 2016). Evaluation and Analysis of Electromagnetic Field Strength in Port Harcourt and its Environs Due to Radio Rivers Transmitter, IOSR Journal of Electronics and Communication Engineering [Online] 11(6), pp.2329. Available: http://www.iosrjournal.org/iosrjecepages/11(6)version-3html

[2] G. Kennedy, B. Davies, S.R.M. Prasanna, Electronic communication system (New Delhi: McGraw-Hill, 2012).

[3] B. O. Omijeh, B. I. Bakare and R. O. Okeke (November2014). Investigating the behavior of Lossy Transmission Lines in Communication Systems, International Journal of Electronic Communication and Computer Engineering [Online]. 6(1), pp. 23-27. Available: http://www.ijecce.org/index.php/issues

[4] Band Scanner GPS. [Online] Available: http://www.deva-fmmonitoring.com/products/band-scanner-gps.

[5] R. Gowri, Electromagnetic fields and waves (New Delhi: S. K. Kataria and Sons, 2008).

[6] Robert E. Collin, Antennas and Radio -wave Propagation, (Mcgraw - Hill Book, First Edition,1985).

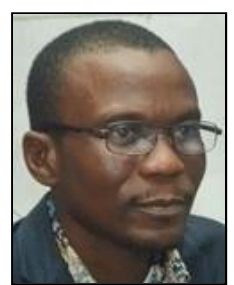

B. I. Bakare holds a Bachelor of Engineering (B.Eng.) Degree in Electrical Engineering; $\mathbf{2}^{\mathbf{1}}$ from Ondo State University, Ado Ekiti, ( Now University of Ado Ekiti, Ekiti State), Master of Engineering (M.Eng.) Degree in Electrical/Electronic Engineering from University of Port Harcourt, Nigeria and he is currently a $\mathrm{PhD}$ (Communication Engineering) Researcher of Nnamdi Azikiwe University (Unizik), Awka, Anambra State. He holds a Category One Wiring License. He is a COREN registered Engineer, a Corporate Member of Nigeria Society of Engineers (NSE), a member of International Association of Engineers (I A ENG) and an active member of Nigeria Institute of Electrical and Electronics Engineers (NIEEE). He is presently a lecturer in the Department of Electrical Engineering, Rivers State University, Port Harcourt., Nigeria

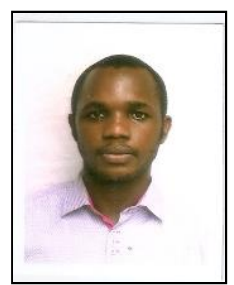

J.C. Ozogbuda was born on the 16th of August, 1993 He graduated from Rivers State University, Port Harcourt, Nigeria with a Second Class Upper Division in Electrical Engineering (Electronics option) in 2017 .He is from Rumuokwurushi, Port Harcourt, Rivers State, Nigeria 